\title{
CULTURAL FACTORS ASSOCIATED WITH THE MANAGEMENT OF BREAST LUMPS AMONGST XHOSA WOMEN
}

\author{
Nosipho Mdondolo \\ MA Cur \\ MA Cur student, Department of Health Studies, University of South Africa \\ Deputy Director: Chronic Diseases, National Department of Health
}

\section{Louise de Villiers}

D Litt et Phil

Senior Lecturer, Department of Health Studies, University of South Africa

Corresponding author: dvilll@unisa.ac.za

\author{
Valerie J Ehlers \\ D Litt et Phil \\ Senior Lecturer, Department of Health Studies, University of South Africa
}

Key concepts: cultural factors; intra-personal factors; management of a breast lump; Xhosa women; health seeking behaviours; advanced breast cancer; Transkei region, South Africa; explanation of health, sickness and the sick role

\begin{abstract}
A qualitative research design and an ethno-nursing research method were used to identify cultural factors influencing Xhosa women's health seeking behaviours associated with breast lumps. Focus group interviews, involving Xhosa women with advanced breast cancer and registered nurses caring for these women, were conducted to obtain data. The research results revealed that perceptions on the significance of the female breast, the meaning of a breast lump and the cause of illness influenced their health seeking behaviours. Other factors included a lack of knowledge about breast lumps, experiences that they had upon discovery of the breast lumps and misconceptions about the consequences of medical treatment. The informants sought treatment from traditional healers prior to seeking medical care from the hospital and/or clinics. By the time they sought medical treatment, the breast lumps had often progressed to advanced ulcerated breast cancer, with poor prognoses and poor treatment outcomes. The data revealed that the informants gained insights due to their experiences. It is therefore suggested that they be involved in health education on the prevention of breast cancer.
\end{abstract}

\section{OPSOMMING}

'n Kwalitatiewe navorsingsontwerp en 'n etnoverpleegkundige navorsingsmetode is gebruik. Die doel was om te bepaal watter kulturele faktore Xhosa vroue se strewe na welstand, wat in verband staan met 'n borsvergroeisel, beïnvloed. Om data in te samel, is fokusgroeponderhoude gevoer met Xhosa vroue wat aan gevorderde borskanker ly en geregistreerde verpleegkundiges wat sodanige vroue versorg. Die navorsingsbevindinge het aan die lig gebring dat persepsies oor die belang van die vroulike bors, die betekenis van 'n borsvergroeisel en die oorsaak van die siekte die strewe na welstand beïnvloed het. Ander faktore sluit in gebrekkige kennis oor borsvergroeisels, belewenisse ten tye van die ontdekking van die borsvergroeisels en wanopvattings oor die gevolge van mediese behandeling. Die informante het behandeling van tradisionele genesers verkry voordat hulle mediese sorg van hospitale en/of klinieke ontvang het. Teen die tyd wat hulle mediese sorg verkry het, het die borsvergroeisels reeds tot gevorderde grade van borskanker ontwikkel. Die prognose en behandelingsuitkomste was derhalwe swak. Daar is bevind dat die informante belangrike insigte vanweë hulle ervarings verkry het. Hulle kan derhalwe betrek word om gesondheidsopvoeding te verskaf ten opsigte van die voorkoming van borskanker. 


\section{INTRODUCTION}

\section{Overview}

According to Sitas (1997:4) there is an increase in the incidence of breast cancer amongst Xhosa women in the former Transkei region of the Eastern Cape Province of the Republic of South Africa (RSA). These women tend to seek medical treatment once their breast lumps have progressed into advanced stages of breast cancer. Early detection and treatment could help in avoiding a mastectomy which could destroy a woman's dignity. The consequences of delayed treatment include advanced breast cancer, metastases and death.

In-depth qualitative research was undertaken to explore the health seeking behaviours of Xhosa women with breast lumps and the factors that influence their health seeking behaviour. The study highlighted the reasons why the research participants delayed seeking medical treatment for their breast lumps. This knowledge will enhance registered nurses' understanding of how their clients perceive and experience breast lumps, and how they react to the discovery of breast lumps.

\section{Contextualisation}

Breast cancer affects women of all race groups worldwide. There is a higher incidence in Western countries than in the developing countries such as the African countries (Facionne, Giancarlo \& Chan, 2000:258; Faulder, 1995:18-19; Sitas, 1997:4). Although the incidence is higher among white women than among black women in South Africa, the incidence appears to be increasing among black women due to lifestyle changes (Burger, 1998:84; Kau, 1997:1; Moormeier, 1996:898). In the United States of America (USA) and the Republic of South Africa (RSA), black women tend to present with breast cancer at a younger age than their white counterparts and many already have advanced stages of breast cancer when they seek medical treatment (Aziz, Hussain, Sohn, Mediavillo, Saitta, Hussain, Brandys, Homel \& Rotman, 1999:439; Bezwoda, 1998:30; El-Thamer \& Wait, 1999:240).

Owor and Kawoya (2000:24) observed that the majority of Ugandan women with breast lumps present for medical treatment when large inoperable malignant breast tumours are already present. Kau (1995:2; 1997:8) reported that this tendency also occurs in the former Bophuthatswana region of the RSA.

Cultural practices, ignorance and socio-economic reasons have been associated with reluctance to seek medical treatment for health problems, including breast lumps (Baider \& Cooper, 1996:36-37; Kau, 1997:23; Lannin, Mathews, Mitchell, Swanson, Swanson \& Edwards, 1998:1806; Mkumatela, 1992:35). Health seeking decisions for breast lumps are influenced by various cultural beliefs and interpretations about the cause and management of an illness (Wright, 1997:1541). Women's decisions on how to manage a breast lump are influenced by cultural beliefs and attitudes about the significance of the female breast, the cause of illness and the potential consequences of having cancer, cancer treatment and losing a breast (Chandra \& Chaturvedi, 1998:41; Mkumatela, 1992:2628; Schlebusch \& Van Oers, 1999:30-34; Thorne \& Murray, 2000:149).

Stepien, Mugwanya, Malgas, Paton and Lucwaba (1998:1) and Sitas (1997:4) mention that there is a great need to identify the factors that contribute towards delays in seeking medical diagnosis and treatment after discovery of a breast lump in specific communities. Once the factors have been established, culture congruent health education campaigns on early detection and treatment of breast lumps could be developed.

\section{RESEARCH DESIGN AND METHOD}

\section{Research design}

A qualitative research design using an ethno-nursing research method (Leininger, 1991:79) was adopted to determine why Xhosa women present late for medical diagnosis and treatment for breast lumps. The focus was specifically on their health seeking behaviours and the intra-personal and cultural factors that influence their health seeking behaviours. The research question for this study was therefore:

What is the nature of the health seeking behaviours of the Xhosa women with breast lumps, and which intrapersonal and cultural factors influence those 
behaviours?

\section{Research purpose}

The purpose was to enhance health professionals' understanding of the intra-personal and cultural factors that contribute towards delayed presentation for medical diagnosis and treatment for breast lumps, and to improve their insights into the related cultural values and practices of the Xhosa patient. The recommendations serve as guidelines for culture congruent care that will contribute towards early detection and treatment of breast lumps.

The objectives of the study were to:

- describe the health seeking behaviours of Xhosa women with breast lumps;

- explore the intra-personal factors that influence health seeking behaviours of Xhosa women with breast lumps; and

- explore the cultural factors that influence health seeking behaviours of Xhosa women with breast lumps.

\section{Definition of concepts}

The key concepts of the research were conceptually defined.

\section{Cultural factors}

Culture refers to a totality of learned and transmitted beliefs, values and life experiences of particular human groups essential to generate and establish credible ethical and moral care knowledge (Leininger, 1990:49). For the purpose of this study the term cultural factors implies values, beliefs, experiences and practices that contribute towards delays in seeking medical care for breast lumps.

\section{Intra-personal factors}

Intra is a prefix that refers to on the inside (Shorter Oxford English Dictionary, 1990:1103). Personal refers to pertaining to, concerning or affecting the individual, person or self; individual; private (Shorter Oxford English Dictionary, 1990:1560). For the purpose of this study the term intra-personal factors imply an individual's inner knowledge, interpretations and experiences of breast lumps that may influence her health seeking behaviour.

\section{Management}

Thompson (1992:538) defines management as the ability to cope or succeed in controlling. For the purpose of this study management implies health seeking behaviour associated with investigating, diagnosing and treating breast lumps, as well as caring for individuals with breast lumps.

\section{Breast lump}

A breast lump is any tumour, mass or swelling found in the breast, namely a palpable increase in the density of mammary tissue (Smeltzer \& Bare, 1999:1268).

\section{Health seeking behaviour}

Health seeking behaviour implies the institutions visited to seek health care, practitioners consulted and any measures taken to treat breast lumps, including home remedies.

\section{Xhosa}

The term Xhosa is derived from the Khoisan (Khoi and San) tribe who were occupiers of the Cape Colony when the 1652 Settlers landed. They were also referred to as Kosa, meaning angry men, sometimes known as the Black peoples or Bantu-speaking peoples with the characteristic click sounds in their language (Elphick \& Gilliomee, 1989:2-3). For the purpose of this study Xhosa refers to a group of people, residing in the former Transkei region of the Eastern Cape of the RSA, who share traditional values, beliefs and practices and speak the Xhosa language.

\section{Assumptions}

The research was based on the following assumptions:

- There is insufficient research evidence about the intra-personal factors and cultural values, beliefs and practices that influence the health seeking behaviours of Xhosa women with breast lumps.

- Xhosa women suffering from breast cancer are valuable sources of information about their own inner world and culture, as well as their health seeking behaviours associated with breast lumps.

- Health professionals' insights into the knowledge and experiences of Xhosa women with breast lumps, and the cultural values, beliefs and practices influencing their health seeking behaviours serve as a foundation for cultural competent nursing care aimed at early detection and treatment of 
breast lumps.

\section{Sampling}

Two research populations were used for this research study.

Adult Xhosa women who had been diagnosed with advanced breast cancer as a result of a delay in seeking medical diagnosis and treatment for a breast lump were used as key informants. They either had to be admitted to the female surgical ward or had to be a client at the surgical out-patient department of the institution where the research was carried out. Thirteen key informants participated in the study. The sample was selected using a purposive sampling method. The ages of the key informants ranged from 31 to 81 years of age (mean age 52,6). Five women were married, five were single, two were widowed and one was separated. Twelve informants had children ranging from two up to ten in number (mean number of children $4,5)$.

The general informants were registered nurses, who were Xhosas themselves, who rendered direct patient care in either the surgical out-patient department or the female surgical ward of the hospital where the key informants received treatment for breast cancer. Four general informants were selected, using a convenience sampling method. Their ages ranged between 40 and 59 years (mean age 49,5 years). They had been employed between four and 12 years (mean employment period 8,5 years). All four were registered general nurses and midwives, and some were also registered as community health, psychiatric and oncology nurses.

Two categories of informants were selected for various reasons. Firstly, the researcher anticipated that key informants might be reluctant to reveal their private thoughts, experiences and actions, considering the sensitive nature of the female breast and health problems affecting the breast. Secondly, although the researcher is also Xhosa-speaking, a measure of distrust was always possible, as nurses are sometimes regarded with suspicion. It is not easy for a researcher to enter the life world of health consumers, especially when sensitive research phenomena, such as breast lumps and cancer, are being investigated. Thirdly, the researcher assumed that the informants might be shy about openly discussing their individual private life experiences in front of others in a focus group interview setting.

The key informants represented the traditional health care system, and a socio-cultural perspective on health, illness and health care. The general informants, although hailing from the same cultural background as the key informants, have been socialised into the professional (biomedical) health care system, and thus represented a scientific perspective. Both the professional (registered nurses) and the generic (Xhosa women with breast lumps) health care systems (Leininger, 1991:37-38) were therefore represented for the purposes of data collection. The responses by the general informants were used to fill the gaps where the key informants refrained from sharing important information with the researcher. The key and general informants' responses were also compared to identify consistencies and inconsistencies.

\section{Data collection}

Data were collected by means of semi-structured focus group interviews. Semi-structured data collection gives participants the freedom to communicate their own perspectives narratively, while also enabling the researcher to ensure that the discussions remain within the boundaries of the problem statement (Greeff, 2002:302-303; Polit \& Hungler, 1995:272). Roos (2000:18) states that this method of data collection allows the informants to talk freely about their experiences, feelings, attitudes and perceptions.

A semi-structured interview guide was developed and pre-tested. Open-ended questions and further probing questions were asked. Probing for more information was based on the information that had been revealed by the respondents. Repeated focus group interviews were conducted with the key informants until data saturation was reached. Thereafter, only one focus group interview was conducted with the general informants. The focus group interviews were recorded on audiotape to capture the informants' original statements.

Leininger's Stranger to Friend Model (Leininger, 1991:92-93) was used as a guideline to establish 
rapport with the informants. Moving from a distrusted person to a trusted friend helps to obtain accurate, sensitive, meaningful and credible data. During the initial stages of each interview, the researcher concentrated on observing the participants' interactions. She introduced the key informants to one another, established a therapeutic environment and collected biographical data. Informed consent was obtained from informants and relevant authorities, and they were assured that anonymity and confidentiality would be maintained. Then the role of primary participation with continued observation was adopted by asking questions and probing further as the need arose. During the focus group interviews with the key informants, the researcher listened, observed and reflected. Decisions on whether to probe further or to move on to another topic and whether to terminate an interview were based on these reflections. Considering the fact that a sensitive issue was investigated and that the key informants were illiterate persons, great care was taken to protect their well-being and selfesteem. The role of primary reflections and reconfirmation of findings with the informants was adopted during data analysis. The informants were also given the opportunity to confirm the researcher's interpretations of their contributions.

To some extent, it was easy to gain the trust of the key informants. The interviews were conducted in Xhosa and the fact that the researcher and informants shared the same Xhosa culture and language, facilitated communication during the focus group interviews. Furthermore, the informants knew the researcher, as they had met during the informants' previous visits to the clinic. However, the key informants did not speak openly about their breasts or aspects of their health seeking behaviours. This posed a potential limitation to the research. However, this limitation was overcome by also having interviews with the general informants, namely registered nurses, providing sources of the data that were difficult to obtain from the key informants.

\section{Data analysis}

Leininger (1991:95) describes phases of an Ethnonursing Data Analysis Guide which was used to guide the researcher during data collection and analysis.
The phase of collecting, describing and documenting raw data entails data collection, management and interpretation (Leininger, 1991:95). In this study, data were collected and recorded as previously discussed. The researcher then transcribed the raw data verbatim, translated it into English and saved it in ASCII-Text format. Units of analysis were specified and the data were then imported into the QSR NUD*IST4.0 data analysis program. Thereafter the researcher read and reread the transcriptions, clustered topics together and identified tentative nodes.

During the phase of identification and categorisation of descriptors and components, the initial actions of data reduction are performed by means of coding and categorising (Leininger, 1991:95). The researcher became immersed in the data and utilised inductive reasoning to create nodes. Node definitions served as guidelines to decide under which node each text unit data should be coded. Categorisation was done by clustering relevant nodes together, based on the discovery of underlying interrelationships between the coded data.

The phase of pattern and contextual analysis entails the scrutinising of data to discover saturation of ideas and elicit similar or different meanings and interpretations. Data are also examined for meaningin-context. Credibility is enhanced by allowing confirmation of interpretations by the research participants (Leininger, 1991:95). The researcher printed out the node reports of each category. The node reports comprised the node names and definitions, and the coded data. These reports were then analysed and the meanings that emerged from the coded data were described. Once the meanings inherent in each node were described by the researcher and validated by the informants, the researcher commenced with the next phase, namely data synthesis.

During the phase of data synthesis findings are interpreted and displayed in a visual format. This results in an organised compressed assembly of data in a thematic format so that conclusions can be reached and decisions made about needed actions (Leininger, 1991:95). In this research, the researcher reduced the categorised data into major themes. The themes explicated the underlying relationships that emerged from the coded and categorised data. She 
then proceeded with data synthesis by discovering the interrelations between the major themes and formulated the research conclusions and recommendations.

\section{Enhancing trustworthiness}

Trustworthiness refers to the extent to which a research study is worth paying attention to, worth taking note of, and the extent to which others are convinced that the findings are to be trusted (Babbie \& Mouton, 2001:276). The criteria by Babbie and Mouton (2001:276-278), Lincoln and Guba (1985:290-300) and Leininger (1991:113) served as guidelines for the researcher.

To enhance credibility the researcher applied data triangulation by interviewing key and general informants. The fact that the Xhosa women and the researcher shared the same culture and language also contributed towards credibility of the research findings. The researcher, who is also a health professional, bracketed existing knowledge and preconceived ideas and especially personal views about suitable health seeking behaviours for breast lumps. In instances where the key informants' viewpoints about breast lumps and health seeking options were different from that of the researcher, she took care to continue to display respect and a non-judgemental attitude.

The researcher's previous knowledge and clinical experience, and the literature that was consulted, enabled her to satisfy the criterion of being knowledgeable about the phenomenon under investigation.

During the focus group interviews a facilitator was asked to assist in describing the research context. Based on this, the researcher realised that she was not able to gain full entry into the life-world of the key informants. The researcher was then able to ensure that the required data were obtained from the general informants, thus applying data-triangulation. The researcher conducted focus group interviews repeatedly until data saturation occurred, namely until the collected data were repeated and confirmation of previously collected data took place (Streubert \& Carpenter, 1999:22-23).
To enhance confirmability, the researcher established an audit trail, by attaching the coding system to a research report and by filing the raw data and node reports. The raw data, the coded data and the researcher's interpretations were scrutinised by research supervisors who acted as independent coders. The categories identified by the researcher were contrasted with those identified by the supervisors. No major discrepancies were identified between these persons' analyses of the data. The researcher's interpretations also were submitted to the research participants to confirm that it reflected their responses.

To enable the reader to judge transferability, the researcher provided in-depth discussions of the data obtained, data analysis and interpretation of the research findings, in a research report.

The fact that the researcher complied with the criteria of data-triangulation and the establishment of an audit trail, enhanced the dependability of this study.

\section{RESEARCH RESULTS}

Three main themes emerged from the study.

\section{Theme 1: Health seeking behaviour}

This theme entails factors that influence health seeking behaviour, and health seeking practices.

\section{Intra-personal factors influencing health seeking behaviour}

The data obtained indicated that the key informants' knowledge and personal experiences influenced their health seeking behaviour after discovery of a breast lump.

\section{- Lack of knowledge}

The key informants' responses indicated that they did not possess knowledge about breast self-examination, the significance of the presence of a breast lump, and the importance of early diagnosis and medical treatment. The key informants mostly discovered their breast lumps themselves. This occurred by chance, as none of them reported any knowledge of breast self-examination procedures. The key informants attached different meanings to the breast lumps that 
they had discovered. While some key informants considered the possibility that breast cancer might be present, others thought that this was an indication of a health problem other than breast cancer. The possibilities mentioned were the presence of an abscess ("ithumba"), a lipoma ("ilifa") or a swollen lymph gland. Some key informants simply did not know what the presence of a breast lump meant. The general informants added another dimension by explaining that denial that a serious health problem such as breast cancer may be present, is often encountered in the health care setting. The key informants did not know that prompt medical diagnosis and treatment were necessary for painless breast lumps. They only sought medical treatment once it became clear that traditional remedies were not effective. The key informants allowed their painless breast lumps to progress into advanced breast cancer before seeking medical treatment.

Sources of information on breast lumps and breast cancer were personal observations and the radio. Some key informants based their interpretations about their breast lumps on personal observations about what had happened to someone else who had a breast lump. The effectiveness of the radio as a health education communication medium appeared to be limited. The general informants explained that the radio is not an effective medium of communication because not all rural households have radios, and some people switch their radios off most of the time in order to spare the batteries. Furthermore, rural people often fail to understand messages being communicated and consequently do not act appropriately after listening to educational health talks on the radio. Surprisingly, the general informants further explained that they did not regard themselves to be effective sources of information on breast lumps and breast cancer, as they did not possess sufficient knowledge on cancer prevention and care. At the time of the data collection it emerged that registered nurses emphasised breastfeeding to mothers, without referring to breast lumps and breast cancer, during general health education sessions provided at the health care institution. The registered nurses' role performance with regard to health education on breast lumps and breast cancer therefore appeared to be ineffective.
The responses by the key informants indicated that negative experiences may have contributed towards the delay in seeking diagnosis and medical treatment for their breast lumps.

The key informants reported negative experiences such as worry, unhappiness, frustration, surprise, and fear of death. Some key informants denied that breast cancer might be present due to an underlying fear of death. It emerged that fear of death was based on previous personal observations of other women dying from breast cancer. The key informants also reported experiences of shame. This experience was related to the stigma that is attached to breast cancer and a fear of losing their femininity.

The meanings attached to the female breast may explain why the key informants initially tended to keep the presence of a breast lump a secret. The key informants explained its significance in terms of femininity, love and intimacy, and breast-feeding. The general informants added to this by stating that the possibility of losing a breast is a devastating idea to a Xhosa woman.

It also emerged that exposing one's breast or having it touched by strangers, especially health professionals, was regarded as an embarrassing experience. This further explains why the key informants were initially reluctant to come forward for diagnosis and medical treatment for their breast lumps.

\section{Cultural factors influencing health seeking behaviours}

Various cultural factors that play a part in the health seeking behaviours of the Xhosa women with breast lumps were identified.

\section{- Cultural beliefs about the causes of breast lumps}

The key informants' views on the cause of illness influenced their decisions on whom to consult in search of health care. The key informants consulted traditional healers, faith healers, private medical practitioners, and hospital doctors.

The key informants conceptualised the cause of a breast lump in terms of the supernatural, sorcery/ witchcraft and equilibrium explanatory models of illness. The possible causes mentioned were

\section{- Personal experiences}


complaints by the ancestors (supernatural causation), the effect of witchcraft (sorcery causation) and other women's jealousy (disequilibrium with the social environment causation). Traditional and faith healers were perceived to be appropriate sources of health care for health problems caused by supernatural forces, sorcery or disharmony with the social environment. Medical treatment was generally sought once it became clear that the remedies prescribed by traditional and faith healers had not been effective, or once complications of traditional remedies had appeared. The key informant, who directly went for medical treatment, did so when breast cancer was already present.

\section{- Cultural values about the significance of the breast}

The key informants explained that they regarded the breast as a significant symbol of femininity, love and intimacy, and nurturing through breast-feeding. According to them, the female breast represents a female body image. The key informants feared the loss of their femininity, their intimate relationships and their appearance. Experiences of embarrassment also occurred and this led to the breast lump initially being kept a secret.

\section{- Cultural beliefs about the consequences of medical treatment}

Fears that diagnostic tests would aggravate breast cancer contributed towards delays in seeking diagnosis and medical treatment for a breast lump. The general informants explained that the key informants were reluctant to come forward for medical treatment because they believe that cancer would spread if the lump would be punctured during a biopsy, since needles and blades are used. Therefore they rather relied on traditional, non-invasive treatment options.

\section{- Significant others}

The key informants, generally received support from their family, husbands or partners and friends in the form of advice to seek health care from a general medical practitioner and a traditional health practitioner. The general informants again explained that medical treatment as an option was considered only once it became clear that care by a traditional health practitioner had been ineffective.
Some key informants indicated that their significant others accompanied them to seek medical treatment for breasts lumps. However occurrences of a woman's partner pressurising her not to seek medical treatment for a breast lump, for fear that a mastectomy might be performed, were also reported.

\section{Health seeking practices}

Health seeking practices include health institutions visited, health practitioners consulted and treatment or remedies taken for a breast lump.

\section{- Health practitioners and institutions utilised}

The medical and the traditional health care systems were utilised complementarily by the key informants, but medical treatment was sought only once a treatable breast lump had developed into advanced breast cancer.

The key informants were reluctant to divulge information about their health seeking practices. The general informants explained that the key informants would first seek health care from a traditional healer or faith healer for various reasons. During a traditional healer's divination, painful procedures are not involved whereas the opposite can be said of modern medical treatment where diagnostic procedures are many, varied and take up to weeks to complete. The traditional healer is accessible and renders culturally congruent care. Those key informants who first consulted a traditional healer finally sought medical diagnosis and treatment once it became clear that the traditional remedies had failed to cure their breast lumps and it had developed into advanced breast cancer. Medical treatment was sought only when the occurrence of visible breast changes namely ulceration, bleeding, fungation and pain prompted the key informants to ultimately seek medical treatment. Complications of traditional remedies also necessitated medical treatment. This included dehydration due to diarrhoea and vomiting, and burns resulting from hot fomentations and steaming.

In contrast, a key informant indicated that she directly consulted a medical practitioner. The general informants explained that such direct consultations usually occurred when a neglected breast lump had progressed into advanced stages of breast cancer. 


\section{- Remedies and treatment received}

According to the general informants, traditional healers prescribed various remedies. If the breast lump was regarded to be an abscess, it was treated with hot fomentations. Stomach washouts and steaming were used to cleanse the system from the effects of witchcraft. Faith healers provided hope of cure through candle lighting while praying for the patient, using holy water and Jeyes fluid (an over-the-counter disinfectant) mixed with milk. Where terminal stages of breast cancer were present, no curative treatment was offered.

The types of medical treatment received include mastectomy, chemotherapy and radiotherapy.

\section{- Length of delay in seeking medical diagnosis and care for a breast lump}

The length of the delay varied between two months and three years. This delay had dire consequences, namely advanced breast cancer, poor treatment results and poor prognosis.

\section{Theme 2: Support systems during treat- ment for breast cancer}

Significant others played an important role in supporting the key informants during their treatment period for advanced breast cancer.

Some key informants' significant others showed concern and support, accompanied them in search for health care, and assisted them during the treatment process. On the other hand, others were neglected and ostracised due to a belief that a woman with a breast lump is being punished for her evil deeds.

\section{Theme 3: Insights gained by the key in- formants that they could share with other women}

The key informants learnt from their experiences and gained insights into the importance of prompt medical treatment for breast lumps. They indicated that they would advise other women with breast lumps to seek medical treatment while the lump is still small and curable, and before it becomes cancerous. In hindsight, the key informants regarded mastectomy, chemotherapy and radiotherapy to be the best treatment op- tions.

\section{CONCLUSION}

From the findings of this study, it emerged that the key informants used the traditional and professional health care systems, and traditional remedies and medical treatments, in a complementary manner. Denial that a serious health problem may be present and a tendency to keep quiet about their breast lumps contributed towards delays in seeking medical diagnosis and treatment. Traditional healers, faith healers or medical practitioners were consulted. Medical practitioners were consulted only once symptoms of breast cancer had appeared or complications of traditional remedies had developed.

The intra-personal factors that influenced the health seeking behaviours of the key informants included lack of knowledge about breast lumps and breast cancer, and personal experiences such as fear and embarrassment. The key informants lacked knowledge about the significance of a breast lump, and the importance of early medical diagnosis and treatment. They feared the possibility of death, loss of their female identity and impaired interpersonal relationships. They also experienced embarrassment and went through a period of denial that breast cancer may be possible.

Cultural factors also influenced the health seeking behaviours of the key informants. The female breast was described to be a significant symbol of the nurturing and loving roles of a woman. Breast lumps and breast cancer were perceived to threaten these female characteristics. Cultural beliefs about the cause of illness, and certain myths that medical interventions could aggravate breast cancer, were reasons why some key informants delayed seeking medical diagnosis and treatment for their breast lumps. Furthermore, the accessibility of traditional healers and their ability to render culture congruent care, also contributed to this phenomenon.

\section{RECOMMENDATIONS}

Based on the findings of this study, the following recommendations were made to ensure that the problem of delayed presentation for medical treatment by a Xhosa woman with a breast lump is addressed. 


\section{Recommendations for clinical practice}

It is recommended that registered nurses should receive in-service education on the prevention, early detection and early treatment of breast cancer. The content should also cover cultural values, beliefs and practices related to health, illness and care with specific reference to reproduction, the reproductive organs, breast lumps and breast cancer. Another important topic is the principles of culture congruent care.

A culturally congruent health education campaign on breast lumps and breast cancer should be developed. The target groups should be traditional and faith healers, Xhosa women and their significant others. Health education should be in the form of face-to-face communication, as media such as the radio may not be effective. Women, who suffer or have suffered from breast cancer because they delayed seeking diagnosis and medical treatment for their breast lumps, could be trained and used as health educators.

There should be collaboration between traditional and faith healers, and health professionals in health care delivery. Traditional and faith healers should be encouraged to refer women with breast lumps for medical treatment. Xhosa women with breast lumps ought to be allowed to receive, simultaneously with medical treatment, traditional remedies that do not impede the effectiveness of medical treatment.

\section{Recommendations for health sciences education}

It is recommended that a course in anthropology be included in health sciences curricula. This course ought to include cultural principles and information relevant to the cultures of a specific area. A course in transcultural nursing or medical anthropology should also be included in curricula. This should include cultural values, beliefs and practices related to human reproduction. Other topics are health, illness and care with reference to the reproductive organs such as the breasts. Learners ought to be encouraged to apply this knowledge to provide culture congruent preventive care to clients.

In-service education programmes should be established to reinforce registered nurses' abilities in effec- tively managing clients from different cultures, with specific reference to clients with breast lumps and breast cancer.

\section{Recommendations for further research}

More in-depth research should be done to investigate the cultural values, beliefs, and practices related to health and illness in general, and breast lumps in particular. The influence of these factors on health seeking behaviours must be explored. It is recommended that a participant observation data collection method should be utilised to enable the researcher to gain lay informants' trust, thus ensuring their willingness to share their beliefs and practices. Alternatively, community members and women with breast cancer could be utilised in data collection, provided that they receive training in interview skills. Ideally, these interviewers should simultaneously supply health education needed by the informants. The focus of further research could also be to gain in-depth information about the experiences that women have upon discovery of a breast lump. In-depth research into the care practices by traditional healers and faith healers, and the underlying belief systems is also required.

\section{CONTRIBUTION OF THE STUDY}

This study contributed to the knowledge base about the health seeking behaviours of the Xhosa women with breast lumps by highlighting the reasons why the key informants delayed seeking medical care for their breast lumps. Registered nurses can utilise this knowledge to better understand how their clients perceive and experience breast lumps, and how they react to its discovery.

As a result of this research, an existing health promotion programme was revised to include specific information about breast cancer prevention, and the importance of early detection and treatment of a breast lump. A breast clinic was also established at the institution where this research was done. The findings that the registered nurses who participated in the study lacked information on breast cancer prevention resulted in the establishment of in-service education on this topic. The Cancer Association of South Africa participated in the above initiatives by distributing information among nurses and the community. 


\section{LIMITATIONS OF THE STUDY}

The limitations of the study are threefold.

Only Xhosa women from the former Transkei region formed part of the population, and a non-random sampling method was used. The sample was not necessarily representative of the population. Therefore, the findings cannot be generalised. However, the researcher did not intend generalising the findings. The in-depth knowledge gained through this research benefited health care delivery as explained in the above section.

The inability of the researcher to gain sufficient trust from the key informants to enable them to fully reveal information about their health seeking behaviours, might have been another limitation. However, the researcher addressed this limitation by also interviewing registered nurses.

The interviews were conducted in Xhosa and the data were translated into English. During the translation process some meanings may have been lost. However, the researcher did submit her interpretations to the informants for validation purposes.

\section{CONCLUSION}

Explorative qualitative research brought to light which intra-personal and cultural factors influence the health seeking behaviour of Xhosa women with breast lumps. Data were generated by interviewing Xhosa women with advanced breast cancer and registered nurses who render health care to women with breast lumps and breast cancer. The phenomenon that Xhosa women seek medical diagnosis and treatment once breast cancer is already present, necessitated this study. The study contributed towards improved health education to the community and in-service training aimed at registered nurses.

\section{REFERENCES}

AZIZ, H; HUSSAIN, F; SOHN,C; MEDIAVILLO, R; SAITTA, A; HUSSAIN, A; BRANDYS, M; HOMEL, P \& ROTMAN, M 1999: Early onset of breast carcinoma in African women with poor prognostic factors. American Journal of Clinical Oncology, 22(5):436440.
BABBIE, E \& MOUTON, J 2001: The practice of social research. Cape Town: Oxford University Press.

BAIDER, L \& COOPER, CL 1996: Cancer and the family. New York: John Wiley.

BEZWODA, WR 1998: Breast cancer in South Africa. Specialist Medicine Oncology, 20:60-61.

BURGER, HM 1998: Changes in risk factors of breast cancer in African women during urbanisation. Potchefstroom: University of Potchefstroom for Christian Higher Education (M Sc Dissertation) CHANDRA, SP \& CHATURVEDI, SK 1998: Psycho-oncology: current issues. Bungalore: Malalur.

ELPHICK, R \& GILLIOMEE, H 1989: The shaping of South African society, 1652-1840. Cape Town: Maskew Miller Longman.

EL-THAMER, MB \& WAIT, KB 1999: Age at presentation of African American and Caucasian breast cancer patients. Journal of American College of Surgeons, 88(3):237-240.

FACIONNE, NC; GIANCARLO, C \& CHAN, L 2000: Perceived risk and health seeking behaviour for breast cancer: a Chinese-American perspective. Cancer Nursing, 23(4):258-267.

FAULDER, C 1995: Breast cancer. A guide to early detection and treatment. Bristol: Virago.

GREEFF, M 2002: Information collection: Interviewing. (In: AS de Vos, H Strydom, CB Fouche \& CSL Delport (Eds) 2002: Research at grassroots for the social sciences and human service professions. Pretoria: Van Schaik, pp. 291-320).

KAU, M 1995: Black cancer patients and the home care givers. Paper presented at the $7^{\text {th }}$ National Cancer Congress at Bloemfontein in September 1995.

KAU, M 1997: An investigation into the effects of cancer and mastectomy on Black women in the former Bophuthatswana. Pretoria: University of South Africa (D Litt et Phil Thesis).

LANNIN, DR; MATHEWS, HF; MITCHELL, J; SWANSON, MS; SWANSON, FH \& EDWARDS, MS 1998: Influence of socio-economic and cultural factors on racial differences in late stage presentation of breast cancer. Journal of the American Medical Association, 279(22):1801-1807.

LEININGER, MM 1990: Ethical and moral dimensions of care. Detroit: Wayne State University Press.

LEININGER, MM 1991: Culture care diversity and universality: A theory of nursing. New York : National League for Nursing Press. LINCOLN YS \& GUBA EG. 1985. Naturalistic inquiry. Newbury Park: Sage.

MKUMATELA, LUZ 1992: The effects of cultural attitudes to Western medicine on compliance. Guilford: Unversity of Surrey (M Sc Disssertation).

MOORMEIER, J 1996: Breast cancer in Black women. Annals of Internal Medicine, 124(10):897-905.

OWOR, P \& KAWOYA, JS 2000: Today's realities in the prevention of cancer in Africa. Paper presented at the Papos 2000 Con- 
ference held in Uganda in September 2000.

POLIT, DF \& HUNGLER, BP 1995: Nursing research: principles and methods; $5^{\text {th }}$ edition. Philadelphia: JB Lippincott.

ROOS, J 2000. Problems explained to determine patients' satisfaction with nursing care. Nursing Update, 25(5):1-32.

SCHLEBUSCH, L \& VAN OERS, H 1999: Psychological stress adjustment and cross-cultural considerations in breast cancer patients. South African Journal of Psychology, 29(1):30-35.

SHORTER OXFORD ENGLISH DICTIONARY 1990: Oxford: Clarendon.

SITAS, F 1997: Cancer in South Africa. Epidemiological comments (produced by the Department of Health in South Africa), 23(3):1-10.

SMELTZER, SC \& BARE, BG 1999: Brunner and Suddarth's textbook of medical-surgical nursing; $9^{\text {th }}$ edition. Philadelphia: JB Lippincott.

STEPIEN, A; MUGWANYA, D; MALGAS, M; PATON, A \& LUCWABA, P 1998: Carcinoma of the breast in the Transkeian African. Paper presented at a Cancer Conference in Poland in January 1998.

STREUBERT, HJ \& CARPENTER, DR 1999: Qualitative research in nursing. Philadelphia: JB Lippincott.

THOMPSON, D 1992: The Pocket Oxford Dictionary; $8^{\text {th }}$ edition. New York: Clarendon.

THORNE, SE \& MURRAY, C 2000: Social constructions of breast cancer. Health Care for Women International, 21:141-159.

WRIGHT, SV 1997: An investigation into the causes of absconding among Black cancer patients. South African Medical Journal, 87(11):1540-1543. 